Research Article

\title{
Experimental and Theoretical Investigations on Progressive Collapse Resistance of the Concrete-Filled Square Steel Tubular Column and Steel Beam Frame under the Middle Column Failure Scenario
}

\author{
Wei Xuan $\left(\mathbb{D},{ }^{1,2}\right.$ Lai Wang $\mathbb{D},{ }^{2}$ Changjiang Liu, ${ }^{1}$ Guoqi Xing $\mathbb{D},{ }^{1}$ Lili Zhang $\mathbb{D}{ }^{3}$ \\ and Haitao Chen (iD ${ }^{2}$ \\ ${ }^{1}$ College of Architectural Engineering, Weifang University, Weifang 261061, China \\ ${ }^{2}$ Shandong Provincial Key Laboratory of Civil Engineering Disaster Prevention and Mitigation, \\ Shandong University of Science and Technology, Qingdao 266590, China \\ ${ }^{3}$ Department of Building Engineering, Zibo Vocational Institute, Zibo 255314, China
}

Correspondence should be addressed to Wei Xuan; xuanwei07@hotmail.com

Received 22 August 2019; Accepted 29 October 2019; Published 15 November 2019

Academic Editor: Ivo Caliò

Copyright (c) 2019 Wei Xuan et al. This is an open access article distributed under the Creative Commons Attribution License, which permits unrestricted use, distribution, and reproduction in any medium, provided the original work is properly cited.

\begin{abstract}
A static loading test was carried out on a 1/3-scale concrete-filled square steel tubular column-steel beam frame (CFSTSBF) specimen with 2 spans to study its progressive collapse behaviors under the middle column failure scenario using the alternate load path method and to examine the failure mode and load transfer and main resistance mechanisms of the residual structure. Then, theoretical models of the specimen, involving the whole collapse process, were developed, and the resistance and deformation relationships of each model were calculated and validated with test results. The results indicated that the specimen collapse process includes the elastoplastic stage, plastic stage, transfer stage, and catenary stage, the beam mechanism and catenary mechanism were the principal mechanisms for the structure against progressive collapse, and catenary action can significantly strengthen structural resistance. The modified theoretical models with higher practical accuracy could be used to assess structural performances against progressive collapse.
\end{abstract}

\section{Introduction}

Progressive collapse can be defined as the propagation of the local initial failure caused by accidents, such as explosion, impact, and seismic, among the structural members of the building, eventually resulting in a larger scope of structural damage and even overall collapse [1-3]. It has two significant characteristics: the uncertainty of the initial failure location and disproportion of the final failure compared to the initial damage. The collapse of the US World Trade Center building is a typical collapse event in which the final damage is disproportionate to the initial; it demonstrates that a progressive collapse would incur serious consequences [4]. The uncertainty of the local damage further increases the analysis difficulty of structural performance against progressive collapse. To this end, the GSA and DOD guidelines suggest the structural progressive collapse resistance can be evaluated by analyzing the performance of the remaining structure formed by the initial damage, utilizing the alternate path method $[5,6]$. The progressive collapse is an instantaneous dynamic nonlinear process which involves nonlinearities of materials and geometries and structural dynamic effects. Hence, the DOD specification [6] proposes to carry out nonlinear dynamic analysis of the remaining structure to obtain structurally accurate dynamic performance. However, such a method is too complicated and 
computationally time-consuming to apply in the practical engineering design.

Guo and $\mathrm{Yu}$ [7] established a nonlinear single-degree-offreedom model to analyze the dynamic response of progressive collapse of a single-column failure structure. Incorporating the impact of the initial failure time, the outcomes of the model were identical with the test results of reinforcement concrete and steel structure, but its application on progressive collapse resistance of the steel-concrete composite structure was not validated. Ferraioli [8] believed structural behaviors were dominated by the first vertical bending mode after a column was removed and built an equivalent inelastic single-degree-of-freedom model to explore the inelastic response and dynamic amplification of the structure. Harry and $\mathrm{Lu}$ [9] developed a simplified theoretical model for a generic beam in a column removal scenario, considering the degradation of strength in the plastic regions and axial restraint effect, and gained its resistance functions. Zhang et al. [10] investigated loadbearing capacity of reinforced concrete flat-plate framed structures with simply supported slabs and fixed supported slabs. They proposed an energy-based model considering the contributions of internal energy dissipation and yield-line effect; then, they analyzed the effect of its parameters on load-bearing capacity, such as reinforcement ratio, slab thickness and aspect ratio on the stiffness, and yield-line resistance. Pham and Tan [11] proposed a simplified analytical model of beam-slab subassembly systems taking into account the contribution of tensile membrane action in slabs to predict structural responses in internal-column removal scenarios. The model had good agreement with the test results. Lu et al. [12] put forward analytical models for reinforced concrete beams with and without slabs to calculate their progressive collapse resistance in the middle column removal scenario. Taking into account the compressive arch action, this model validated with test and numerical results can be used for practical design of the RC structure. Flexural and compressive arch are the different mechanisms against progressive collapse, respectively. A theoretical method [13], incorporating these mechanisms, was introduced to value the collapse resistance of reinforced concrete frame structures in static progressive collapse.

Such achievements mentioned above can be used for estimating the collapse resistance of reinforced concrete and steel structures, but limited on composite structures. On the basis of the method that assessed the structural dynamic response using the nonlinear static analysis approach, developed by Izzuddin et al. [14], the present paper conducted a static loading test on concrete-filled square steel tubular column-steel beam frame (CFSTSBF) specimen to explore its progressive collapse resistance under the middle column removal scenario. The collapse process of the CFSTSBF specimen can be divided into four stages, by discussing its deformation shapes, failure patterns, and load transfer and resistance mechanisms in the test duration. Then, a theoretical model for each stage was proposed to calculate resistance functions, i.e., resistance and deformation relationships of the specimen.

\section{Experimental Program}

2.1. Specimen Details. According to the Chinese steel structure design code, a single-story $1 / 3$-scale CFSTSBF specimen with two spans was built and its layer height and span length were $1100 \mathrm{~mm}$ and $1650 \mathrm{~mm}$, as illustrated in Figure 1.

As depicted in Figure 1, the section dimensions of side columns (column A and column C), inside column (column B), and steel beams were $200 \times 200 \times 10,150 \times 150 \times 8$, and $160 \times 88 \times 6$, respectively (overall depth $(h) \times$ flange width $(b) \times$ web thickness $\left.\left(t_{w}\right)\right)$. The side columns adopt a larger section size to ensure the loading process is not interrupted due to column failure, and to provide the beam with effective supports and constrains [15].

The average cubic compressive strength of concrete was $40.8 \mathrm{MPa}$, and the yield and tensile strengths were $f_{y}=283.0 \mathrm{MPa}$ and $f_{u}=385 \mathrm{MPa}$ for the beam flange, $f_{y}=264.0 \mathrm{MPa}$ and $f_{u}=364.0 \mathrm{MPa}$ for the beam web, $f_{y}=282.0 \mathrm{MPa}$ and $f_{u}=352.0 \mathrm{MPa}$ for the side column, $f_{y}=273.0 \mathrm{MPa}$ and $f_{u}=347.0 \mathrm{MPa}$ for the inside column, and $f_{y}=1030 \mathrm{MPa}$ and $f_{u}=1156 \mathrm{MPa}$ for the high-strength bolt.

2.2. Loading System. To study the progressive collapse resistance of the CFSTSBF specimen, a downward vertical constantly increasing load was applied on the top of column B which represented the initial failure component. As shown in Figure 2, the specimen was fixed on the ground beam, through, respectively, anchoring its column A and column C with 8 high-strength bolts whose diameter and tensile strength were $35 \mathrm{~mm}$ and $1200 \mathrm{MPa}$, and loading device adopted the FCS2201000-500 electrohydraulic servo system with a stroke of $\pm 250 \mathrm{~mm}$ and maximum load of $500 \mathrm{kN}$. The preloading was conducted on the specimen before the formal loading; its value was taken as $10 \%$ of the initial yield load value of the numerical model with same parameters, and its duration was $10 \mathrm{~min}[16,17]$ to check whether the loading device and the test instrument were working properly. Then, a displacement-control load was applied on the top of column $\mathrm{B}$, whose vertical support was removed before loading. The loading rate was $2 \mathrm{~mm} / \mathrm{min}$ before the specimen yielded, and after that, it was adjusted to $5 \mathrm{~mm} / \mathrm{min}$; the loading duration was $4 \sim 6 \mathrm{~min}$ to ensure the deformation is stable and there is enough time to observe and record the test phenomenon. When the load value could not continue to increase and the specimen showed significant damage, the test terminated.

\subsection{Test Results}

2.3.1. Test Phenomenon and Failure Patterns. In this test, before the vertical displacement of column $\mathrm{B}\left(w_{P}\right)$ reached $20 \mathrm{~mm}$, the specimen remained elastic. When $w_{P}=40 \mathrm{~mm}$, the vertical load $(P)$ applied on the top of column B was $190.117 \mathrm{kN}$ and a slight deformation was detected at the bottom flange of the beam in the hogging moment region (HMR), i.e., the joint region of column A and column C. When $w_{P}=100 \mathrm{~mm}, P=$ $192.531 \mathrm{kN}$ and the buckling was observed at the top flange of the beam in the sagging moment region (SMR), i.e., the joint region of column B, as shown in Figure 3(a). 


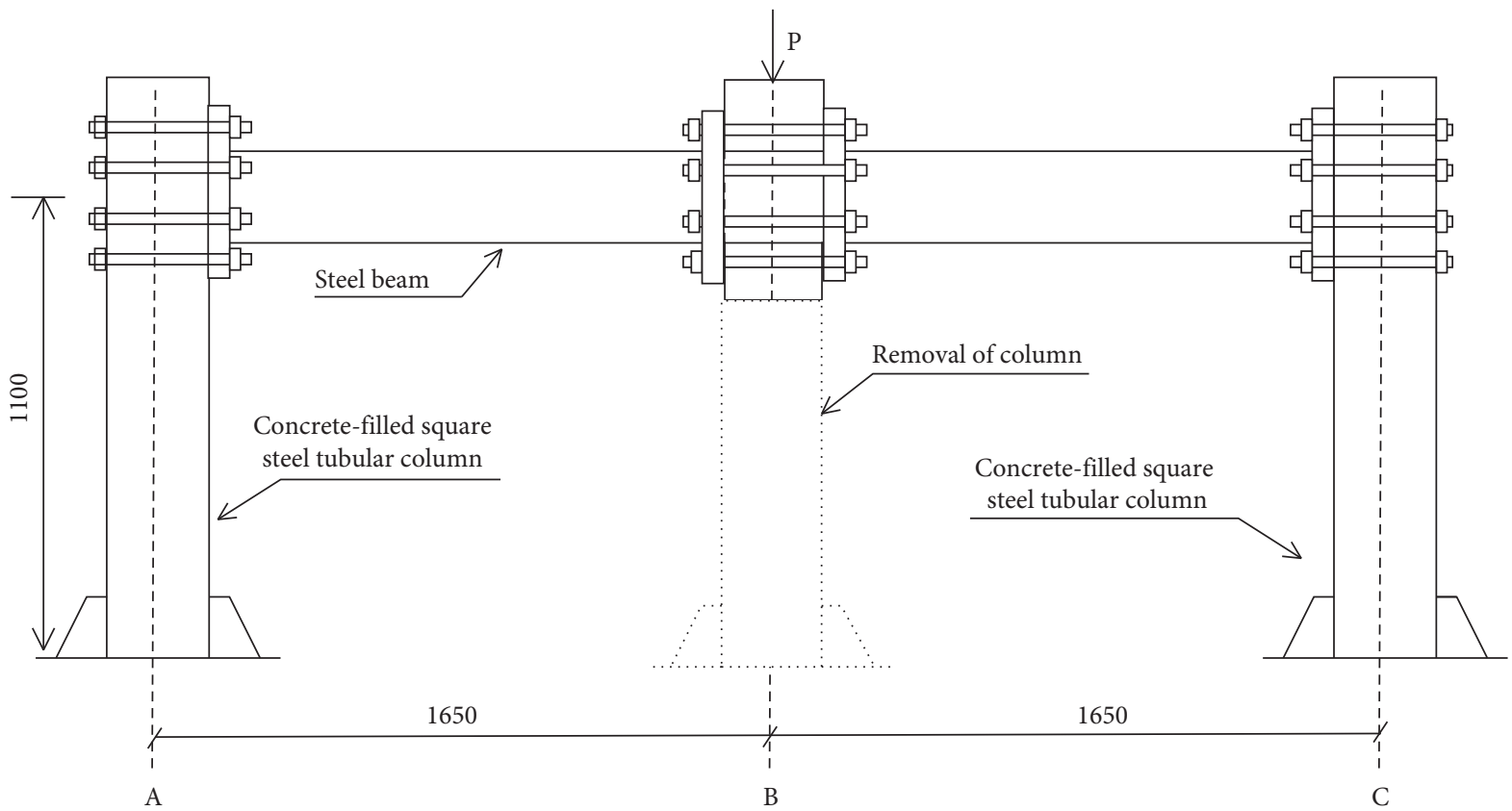

(a)

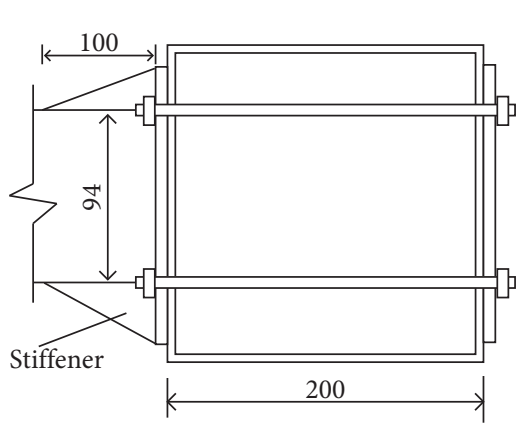

Top view of side column

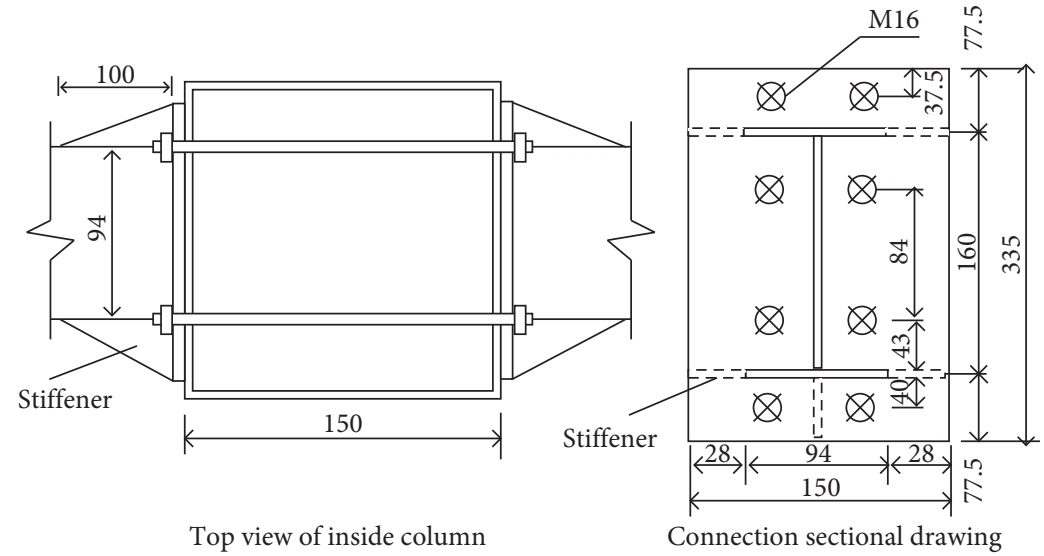

(b)
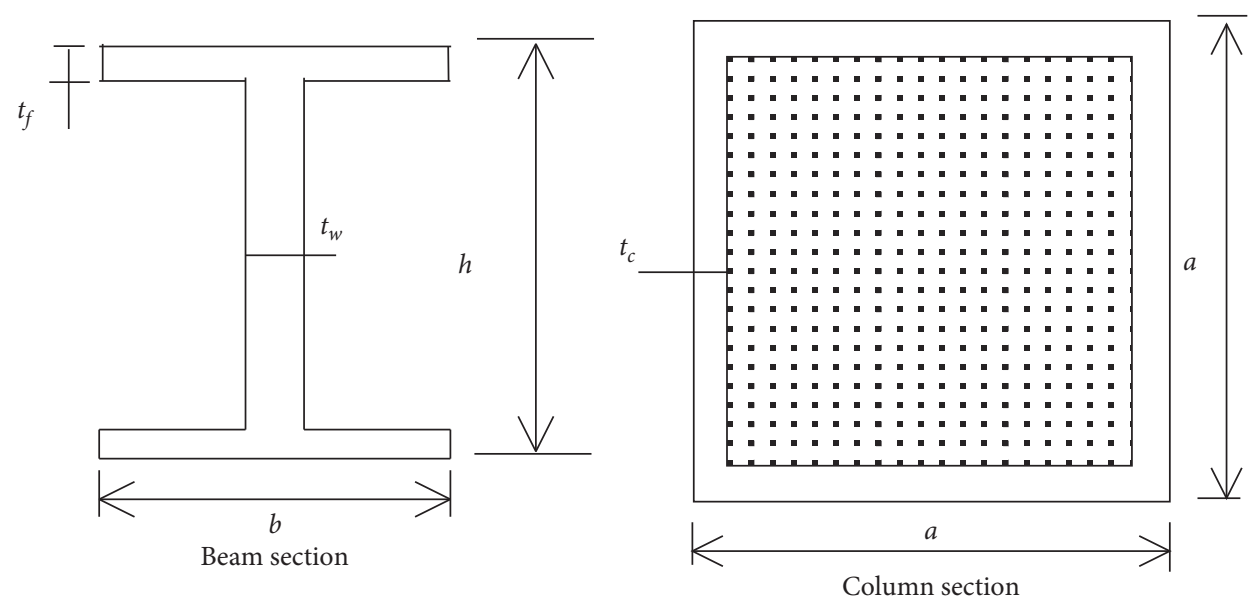

(c)

FIGURE 1: Geometric parameters of the CFSTSBF specimen (unit: mm). (a) Elevation drawing. (b) Connection details. (c) Beam and column sectional geometric dimensions. 


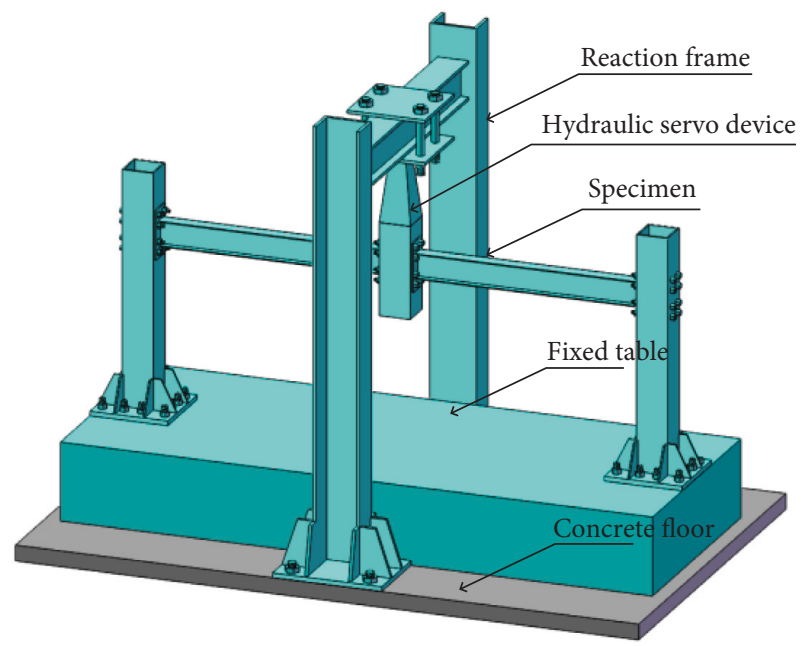

Figure 2: Test setup.

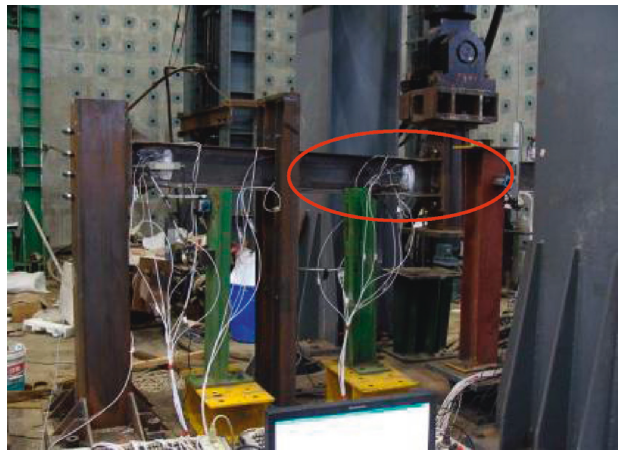

(a)

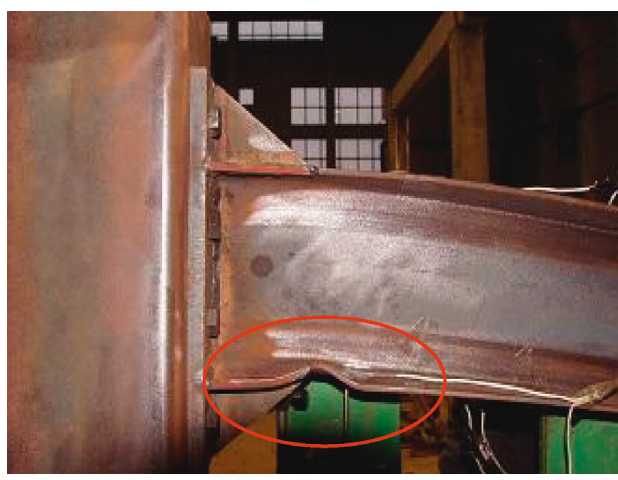

(c)

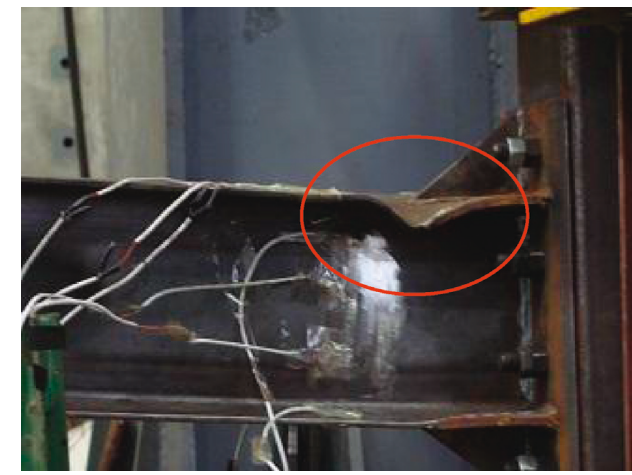

(b)

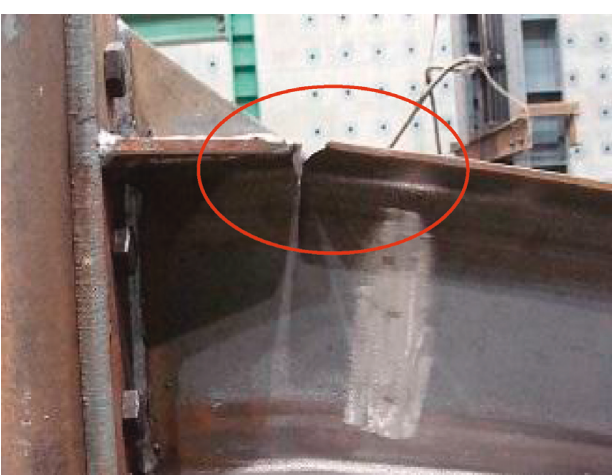

(d)

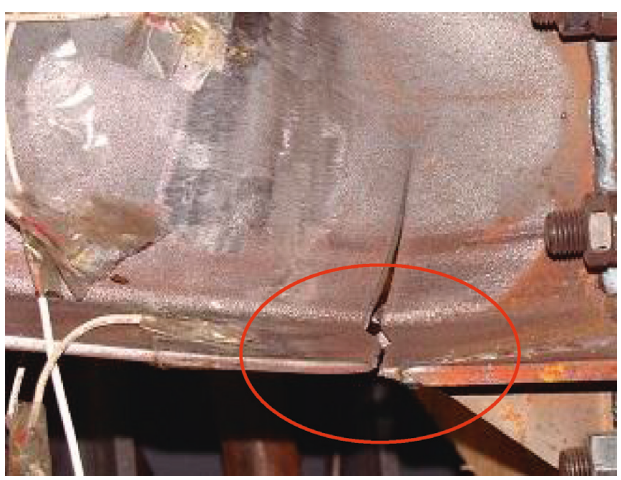

(e)

Figure 3: Failure modes of the CFSTSBF. (a) Top flange buckling in the HMR. (b) Bottom flange buckling in the SMR. (c) Top flange buckling in the HMR. (d) Top flange fracture in the SMR. (e) Bottom flange fracture in the HMR. 
When $w_{P}=150 \mathrm{~mm}, P=200.545 \mathrm{kN}$ and the bottom and top flanges of the beam in the SMR and HMR buckled severely, as shown in Figures 3(b) and 3(c). When $w_{P}=310 \mathrm{~mm}, P=220.323 \mathrm{kN}$ and a crack was observed at the bottom flange of the beam in the SMR. When $w_{P}=320 \mathrm{~mm}$, the top flange of the beam in the HMR cracked. When $w_{P}=330 \mathrm{~mm}$, the cracks of the top and bottom flange in the HMR and SMR elongated to the web (Figure 3(e)) and the vertical load could not be further increased, and thus, the loading was terminated. Cracks that extended to the web of the steel beam from the flange incurred the failure of the CFSTSBF specimen.

2.3.2. Load-Displacement Analysis. Load-displacement relationship of the CFSTSBF specimen, i.e., the resistance curve, is illustrated in Figure 4. The elastoplastic stage $\left(w_{P}<20 \mathrm{~mm}\right)$ is the beginning stage of the loading process, and the load rose linearly with the displacement increase. At this stage, the beam mechanism played an important role against structural collapse; that is, the principal anticollapse resistance at this stage was bending moment. The resistance curve then entered the plastic stage $\left(20 \mathrm{~mm}<w_{P}<95 \mathrm{~mm}\right)$, and the load grew with the displacement increase, but the increasing rate was lower in this stage than in the elastoplastic stage. The behavior of the specimen was governed by bending moment, and plastic hinges developed at joints of the SMR and the HMR in turn at the end of this stage. At the transient stage $\left(95 \mathrm{~mm}<w_{P}<190 \mathrm{~mm}\right)$, the third stage of the resistance curve, plastic hinges had already formed and the bending moment could not increase further. Axial tension developed to withstand the increasing load, and the performance of the specimen was governed by a combination of bending moment and tensile force. The catenary stage $\left(190 \mathrm{~mm}<w_{P}<330 \mathrm{~mm}\right)$ is the last stage of the resistance curve, and the load decreased to $137 \mathrm{kN}$ from $220.323 \mathrm{kN}$ with the displacement increase from $310 \mathrm{~mm}$ to $330 \mathrm{~mm}$. The main anticollapse resistance was tensile force at this stage.

\section{Theoretical Analysis}

\subsection{Parameter Analysis and Collapse Stage Divisions}

3.1.1. Parameter Analysis. After a vertical member failure, its former bearing load becomes unbalanced force and exerts on the remaining structure. The redistribution ability of the unbalanced load is influenced by the stiffness of the horizontal member (i.e., the frame beam). As is well known, the stiffness of the beam is mainly derived from the steel beam, and it is also affected by the constraint of the beam end [18] and the plasticity of the steel beam section. The stiffness of the steel beam would decrease, while the plasticity of the steel beam section extends [19], and its reduction factors are shown in Table 1.

3.1.2. Collapse Stage Divisions. As described in experimental analysis, the collapse process of the CFSTSBF specimen could be divided into four stages, and they were in turn the elastoplastic stage, plastic stage, transient stage, and catenary stage, as shown in Figure 5.

At the elastoplastic stage $(\mathrm{OA})$ and plastic stage $(\mathrm{AB})$, structural behaviors were governed by the beam mechanism, whose carrying capacity was affected by flexural stiffness and boundary conditions [20]. At the transient stage (BC), the resistance function was mainly composed of bending moment and axial tension force, and their relationship should be determined firstly for the purpose of calculating the resistance function. At the catenary stage (CD), the steel beam was in the full-section tension state, and axial tension force played a leading role against collapse.

3.2. Collapse Models. The progressive collapse of a structure is a dynamic development process which can be divided into several collapse stages. Due to the fact that structural resistance and boundary conditions vary with progressive collapse development, it is difficult to accurately simulate the structural response using a unified model. Hence, this research proposed theoretical models of the CFSTSBF specimen which varied with collapse stages, defined their applicable conditions, and calculated the resistance function of each model.

3.2.1. Elastoplastic Stage. The analysis model of the CFSTSBF specimen in this stage is detailed in Figure 6, and it should satisfy the following assumptions:

(1) The constraints at both ends of the steel beam were ideal fixed-end constraints with sufficient strength and stiffness

(2) The sectional deformation conformed to the Euler-Bernoulli assumption, and the position of the sectional neutral axis was kept constant in this stage

(3) Because the longitudinal dimension of the beam was much larger than the lateral dimension in magnitude, the stress of $\sigma_{y}, \sigma_{x}$, and $\tau_{x y}$ could be ignored compared with the others, i.e., $\sigma_{y}=\sigma_{x}=\tau_{x y}=0$

(4) The steel model adopts the ideal elastoplastic constitutive model, and its stress-strain relationship is illustrated in Figure 7

(5) Ignoring the displacement caused by the axial force of the beam, the axial displacement of the beam was mainly caused by the vertical deformation

According to the aforementioned basic assumptions, the deflection curve that satisfied the boundary conditions of this stage is as follows:

$$
w(x)=\sum_{n=1}^{\infty} a_{n}\left(1-\cos \frac{2 n \pi x}{L}\right) .
$$

The deformation energy $(U)$, potential energy $(V)$, and total potential energy $(\Pi)$ of the CFSTSBF specimen are given by 


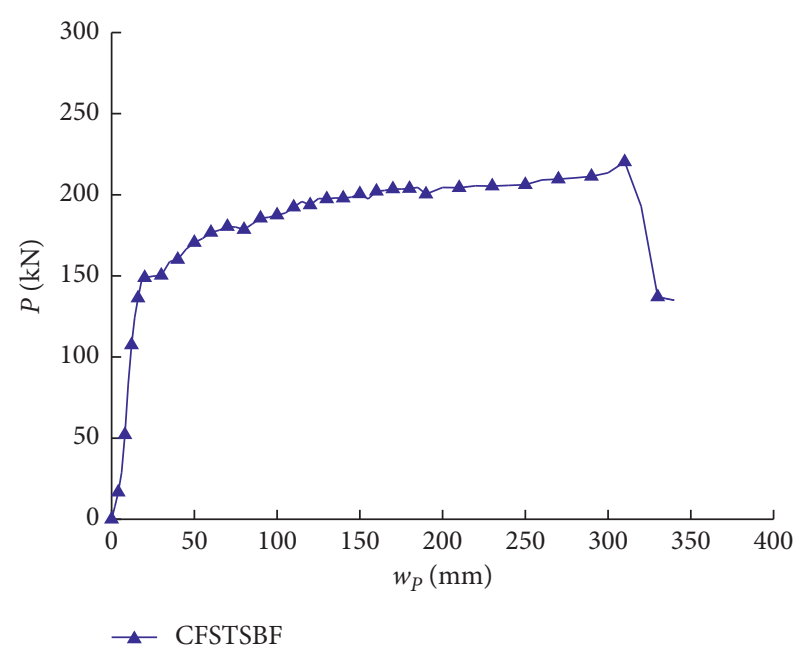

FIgURE 4: Resistance curve of the CFSTSBF specimen.

TABle 1: Flexural stiffness reduction factors $(\mu)$.

\begin{tabular}{lccc}
\hline & \multicolumn{3}{c}{$L / D$ (span-depth ratio) } \\
& 10 & 15 & 20 \\
\hline$\mu_{\mathrm{EP}}$ & 0.085 & 0.179 & 0.335 \\
$\mu_{P}$ & 0.033 & 0.071 & 0.135 \\
\hline
\end{tabular}

Note: $\mu_{\mathrm{EP}}$ represents the flexural stiffness reduction factor in the elastoplastic stage; $\mu_{P}$ represents the flexural stiffness reduction factor in the plastic stage.

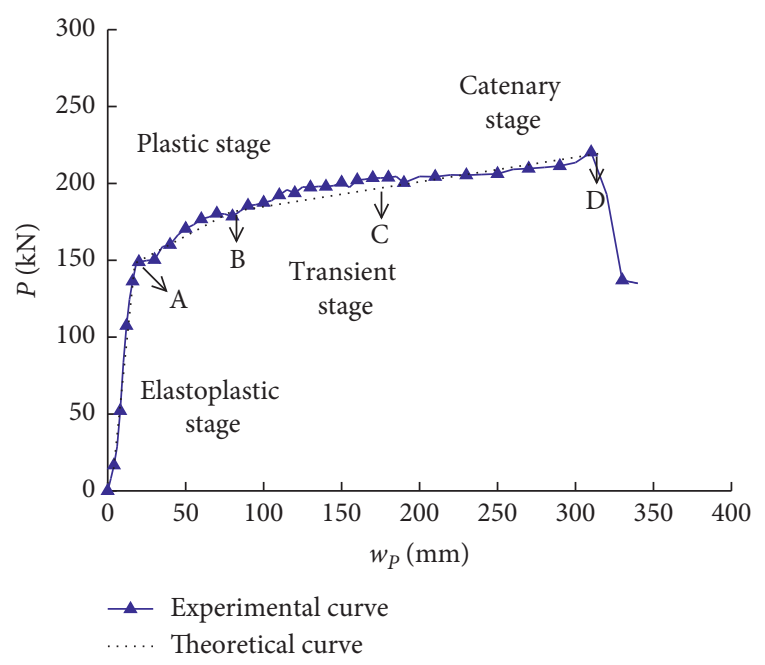

FIGURE 5: Experimental and theoretical resistance curves of the CFSTSBF specimen.

$$
\begin{aligned}
& U=\int_{L} \frac{1}{2} \mu_{\mathrm{EP}} k_{E} L\left(\frac{\partial^{2} w}{\partial x^{2}}\right)^{2} \mathrm{~d} l, \\
& V=-\frac{1}{2} P w_{p}=-\frac{1}{2} P \sum_{n=1}^{\infty} a_{n}\left(1-\cos \frac{2 n \pi x_{P}}{L}\right),
\end{aligned}
$$

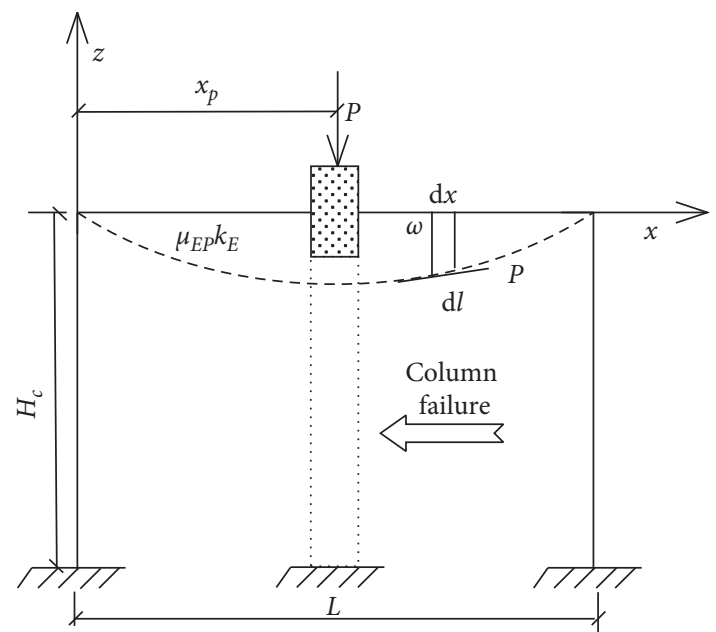

Figure 6: Analysis model in the elastoplastic stage.

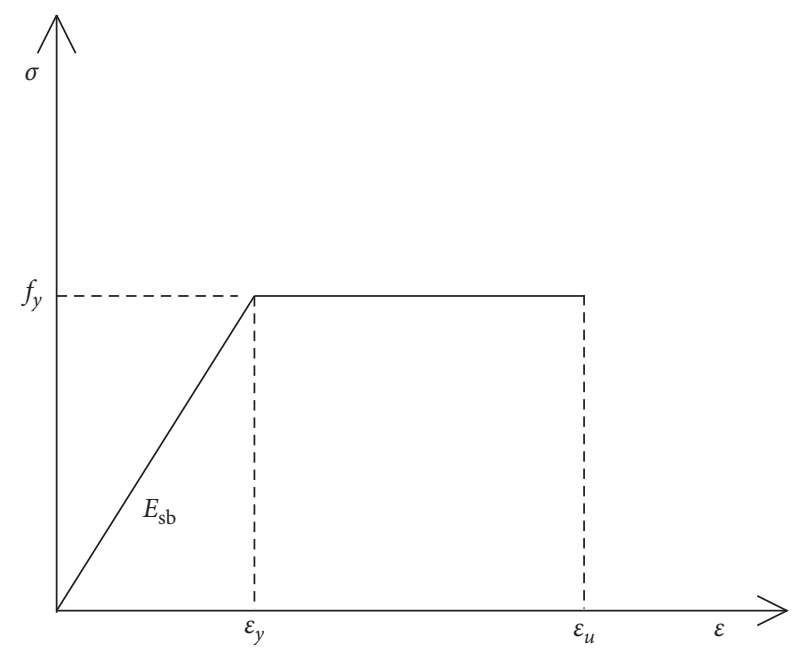

Figure 7: Stress-strain relationship of steel in the elastoplastic stage.

$$
\prod=U+V=\frac{4 \pi^{4} \mu_{\mathrm{EP}} k_{E}}{L^{2}} \sum_{n=1}^{\infty} n^{4} a_{n}^{2}-\frac{1}{2} P \sum_{n=1}^{\infty} a_{n}\left(1-\cos \frac{2 n \pi x_{P}}{L}\right)
$$

Based on the principle of minimum potential energy, the minimum requirement against progressive collapse of the model was obtained:

$$
a_{n}=\sum_{n=1}^{\infty} \frac{P L^{2}}{16 \pi^{4} n^{4} \mu_{\mathrm{EP}} k_{E}}\left(1-\cos \frac{2 n \pi x_{P}}{L}\right) .
$$

Then, the vertical displacement equations of the steel beam deflection curve and the failure point could be calculated as 


$$
\begin{aligned}
w(x) & =\sum_{n=1}^{\infty} \frac{P L^{2}}{16 \pi^{4} n^{4} \mu_{\mathrm{EP}} k_{E}} \cdot\left(1-\cos \frac{2 n \pi x_{P}}{L}\right)\left(1-\cos \frac{2 n \pi x}{L}\right) \\
w_{P} & =\sum_{n=1}^{\infty} a_{n}\left(1-\cos \frac{2 n \pi x_{p}}{L}\right)=\frac{P L^{2}}{384 \mu_{E P} k_{E}}
\end{aligned}
$$

where $\mu_{\mathrm{EP}}$ represents the flexural stiffness reduction factor of the steel beam in this stage, and it could be obtained from Table 1. $k_{E}$ represents the bending stiffness of steel beams that could be calculated by the following equation:

$$
k_{E}=\frac{E_{\mathrm{sb}} I_{\mathrm{sb}}\left(E_{\mathrm{sc}} I_{\mathrm{sc}}+0.6 E_{c} I_{\mathrm{cc}}\right)}{2 E_{\mathrm{sb}} I_{\mathrm{sb}} H_{c}+\left(E_{\mathrm{sc}} I_{\mathrm{sc}}+0.6 E_{c} I_{\mathrm{cc}}\right) L},
$$

where $E_{\mathrm{sb}}$ is the elastic modulus of the steel beam, $I_{\mathrm{sb}}$ is the sectional moment of inertia of the steel beam, $A_{\mathrm{sb}}$ is the sectional area, $L$ is the beam span, $I_{c}$ is the column sectional moment of inertia, $H_{c}$ is the column height, $E_{\mathrm{sc}}$ and $E_{c}$ are the elastic modulus of the steel tube and concrete, and $I_{\mathrm{sc}}$ and $I_{\mathrm{cc}}$ are the sectional moment of inertia of the steel tube and concrete.

3.2.2. Plastic Stage. The analysis model of the CFSTSBF specimen at this stage is shown in Figure 8, and it should meet the following assumptions:

(1) The restraining effect of columns and the influence of plastic extension of the steel beam section should be taken into account when calculating the flexural stiffness of the steel beam, while the influence of axial force was ignored

(2) The plastic hinges occurred at beam ends first and then at the midspan of the beam, while the other parts still remained elastic

Based on the assumptions mentioned above, the deflection curve that satisfied the boundary conditions of this stage is as follows:

$$
\Delta w(x)=\sum_{n=1}^{\infty} a_{n} \sin \frac{n \pi x}{L} .
$$

The deformation energy $(U)$, potential energy $(V)$, and total potential energy $(\Pi)$ of the CFSTSBF specimen are given by

$$
\begin{aligned}
& U=\iiint_{v} \sigma \varepsilon \mathrm{d} v=\frac{\pi^{4} k_{\mathrm{ce}, P}}{4 L^{2}} \sum_{n=1}^{\infty} n^{4} a_{n}^{2}, \\
& V=-\frac{1}{2} \Delta P_{B} w_{p}=-\frac{1}{2} \Delta P_{B} a_{n} \sum_{n=1}^{\infty} \sin \frac{n \pi x_{P}}{L}, \\
& \Pi=U+V=\frac{\pi^{4} k_{\mathrm{ce}, P}}{4 L^{2}} \sum_{n=1}^{\infty} n^{4} a_{n}^{2}-\frac{1}{2} \Delta P_{B} a_{n} \sum_{n=1}^{\infty} \sin \frac{n \pi x_{P}}{L} .
\end{aligned}
$$

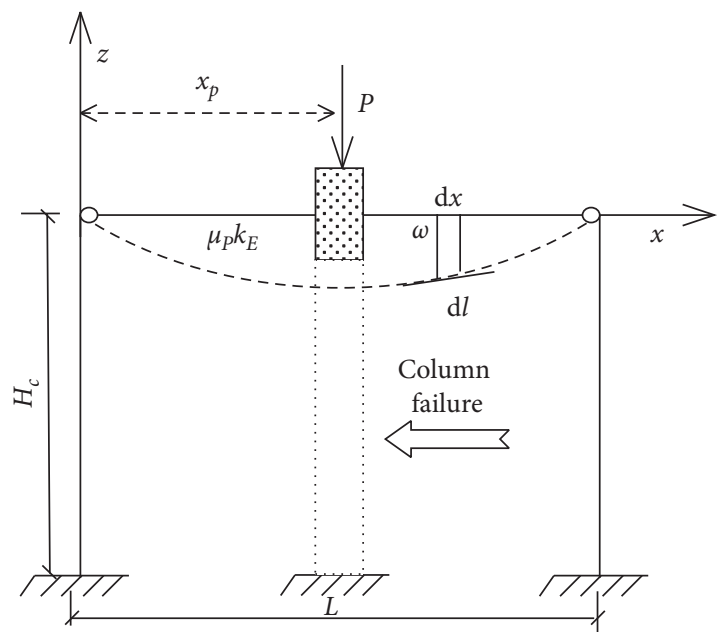

Figure 8: Analysis model in the plastic stage.

According to the principle of minimum potential energy, the minimum requirement against progressive collapse of the model was obtained:

$$
a_{n}=\frac{\Delta P_{B} L^{2}}{n^{4} \pi^{2} \mu_{P} k_{E}} \sin \frac{n \pi x_{P}}{L} .
$$

Then, the vertical displacement equations of the steel beam deflection curve and the failure point could be determined by

$$
\begin{aligned}
\Delta w(x) & =\sum_{n=1}^{\infty} \frac{\Delta P_{B} L^{2}}{n^{4} \pi^{2} \mu_{P} k_{E}} \sin \frac{n \pi x_{P}}{L} \sin \frac{n \pi x}{L}, \\
\Delta w_{P_{B}} & =\sum_{n=1}^{\infty} \frac{\Delta P_{B} L^{2}}{n^{4} \pi^{2} \mu_{P} k_{E}} \sin ^{2} \frac{n \pi}{2}=\frac{\Delta P_{B} L^{2}}{96 \mu_{P} k_{E}}, \\
\Delta P_{B} & =\frac{1}{2}\left(P+P_{A}\right) \leq \frac{1}{L}\left(M_{u}+M_{y}\right), \\
M_{y} & =\frac{f_{y}}{6}\left[b h^{2}-\frac{1}{h}\left(b-t_{w}\right)\left(h-2 t_{f}\right)^{3}\right], \\
M_{u} & =\frac{f_{y}}{4}\left[4 b t_{f}\left(h-t_{f}\right)+t_{w}\left(h-2 t_{f}\right)^{2}\right],
\end{aligned}
$$

where $M_{y}$ and $M_{u}$ are the sectional yield and ultimate flexural moment of the steel beam, respectively; $b, h, t_{f}$, and $t_{w}$ are the geometric dimensions of the steel beam section, as illustrated in Figure 1(c); and $\mu_{P}$ is the flexural stiffness reduction factor which could be found in Table 1 .

The total displacement of the failure point ranging from the elastoplastic to the plastic stage could be calculated as

$$
w=w_{A}+\Delta w_{P_{B}},
$$

where $\Delta P_{A}$ is the vertical load increment and $P_{A}$ and $P_{B}$ are the load values at the start and end points of the plastic stage, respectively. 
3.2.3. Transient Stage. The analysis model of the CFSTSBF specimen in this stage is illustrated in Figure 9, and it should meet the following assumptions:

(1) The restraining effect of columns, the influence of plastic extension of the steel beam section, and the contribution of axial force should be taken into account when calculating the flexural stiffness of the steel beam

(2) The plastic hinges formed at both ends and midspan of the beam in turn, while the other parts were still in the elastic state

Depending on the assumptions mentioned above, the deflection curve that met the boundary conditions of this stage is as follows:

$$
\Delta w(x)=\sum_{n=1}^{\infty} a_{n} \sin \frac{n \pi x}{L} .
$$

The deformation energy $(U)$, potential energy $(V)$, and total potential energy $(\Pi)$ of the CFSTSBF specimen are given by

$$
\begin{aligned}
U= & \iiint_{v} \sigma \varepsilon \mathrm{d} v=\frac{\pi^{4} \mu_{P} k_{E}}{4 L^{2}} \sum_{n=1}^{\infty} n^{4} a_{n}^{2}, \\
V= & -\frac{1}{2} \Delta P_{C} \Delta w_{p}=-\frac{1}{2} \Delta P_{C} a_{n} \sum_{n=1}^{\infty} \sin \frac{n \pi x_{P}}{L}, \\
\prod= & U+V=\frac{N \pi^{2}}{4 L} \sum_{n=1}^{\infty} n^{2} a_{n}^{2}+\frac{\pi^{4} \mu_{T} k_{E}}{4 L^{2}} \sum_{n=1}^{\infty} n^{4} a_{n}^{2} \\
& -\frac{1}{2} \Delta p_{C} \sum_{n=1}^{\infty} a_{n} \sin \frac{n \pi x_{P}}{L} .
\end{aligned}
$$

Based on the principle of minimum potential energy, the minimum requirement against progressive collapse of the model was obtained:

$$
a_{n}=\frac{\Delta P_{C} L^{2}}{n^{2} \pi^{2} L N+n^{4} \pi^{4} \mu_{T} k_{E}} \sin \frac{n \pi x_{P}}{L} .
$$

When the steel beam section was fully yielded [20], its axial force can be expressed as

$$
N=\frac{r-\mathrm{mr}^{2}}{1-\mathrm{mr}^{2}} N_{u}=\frac{r-\mathrm{mr}^{2}}{1-\mathrm{mr}^{2}} f_{y} A_{s} .
$$

Equation (24) can be described as

$$
a_{n}=\frac{\Delta P_{C} L^{2}\left(1-\mathrm{mr}^{2}\right) \sin \left(n \pi x_{P} / L\right)}{\psi_{1}+\psi_{2}},
$$

where $\quad \psi_{1}=n^{2} \pi^{2} L\left(r-\mathrm{mr}^{2}\right) f_{y} A_{s} \quad$ and $\quad \psi_{2}=n^{4} \pi^{4} k_{\mathrm{ce}, T}$ $\left(1-m r^{2}\right)$.

Then, the vertical displacement equations of the steel beam deflection curve and the failure point could be calculated as

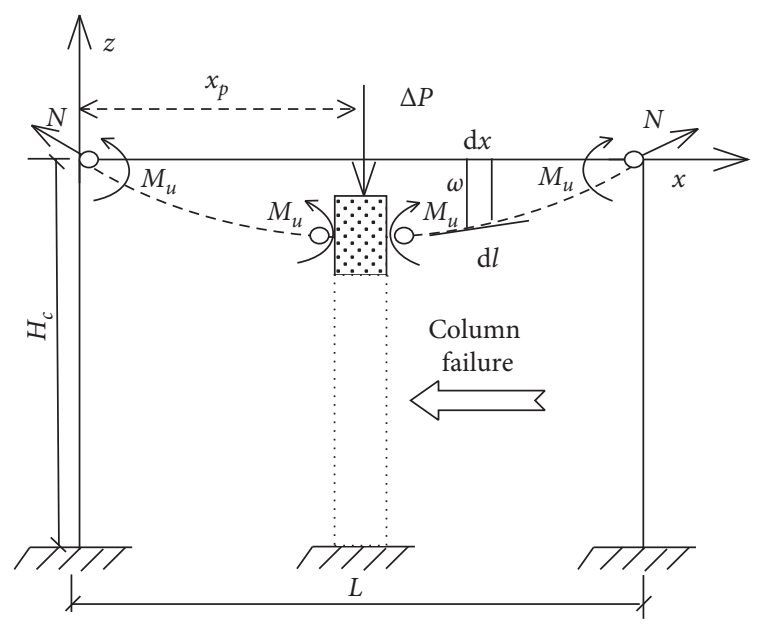

FIgUre 9: Analysis model in the transient stage.

$$
\Delta w(x)=\sum_{n=1}^{\infty} \frac{\Delta P_{C} L^{2}\left(1-\mathrm{mr}^{2}\right) \sin \left(n \pi x_{P} / L\right) \sin (n \pi x / L)}{\psi_{1}+\psi_{2}},
$$

$$
\Delta w_{P_{C}}=\sum_{n=1}^{\infty} \frac{\Delta P_{C} L^{2}\left(1-\mathrm{mr}^{2}\right) \sin ^{2}(n \pi / 2)}{\psi_{1}+\psi_{2}} .
$$

The total displacement of the failure point ranging from the elastoplastic to the transient stage and the resistance force in this stage could be calculated as

$$
\begin{aligned}
w & =w_{B}+\Delta w_{P_{C}}, \\
P_{C} & =P_{B}+\Delta P_{C} .
\end{aligned}
$$

The strain value of the compressive flange of the steel beam section grew to 0 , which indicated the progressive collapse came to the end of this stage, and the axial force was described as

$$
\varepsilon_{N_{1}}=\varepsilon_{M_{u}}=\frac{M_{u}}{\mu_{p} k_{e} L} .
$$

The displacement of the failure point in this stage was calculated as

$$
w_{C}=\frac{L}{2} \sqrt{\frac{M_{h o g}}{k_{c e, P} L}\left(\frac{M_{h o g}}{k_{c e, P} L}+2\right)} .
$$

3.2.4. Catenary Stage. The catenary stage was the last but the important stage of the structural collapse process against progressive collapse. During this stage, the catenary effect began to work and strengthen structural capacity against progressive collapse. The analysis model of the CFSTSBF specimen in this stage is illustrated in Figure 10, and it should meet the following assumptions:

(1) The joint had sufficient strength and rotation ability; for example, the joint did not fail until the structure was damaged.

(2) As shown in Figure 11, the axial stress-strain relationship was represented by a double-fold line- 


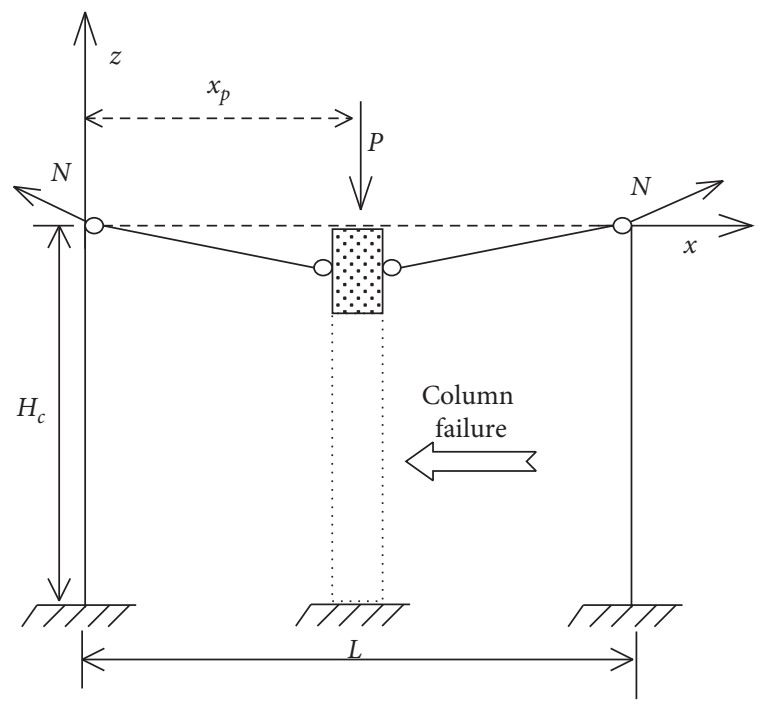

Figure 10: Analysis model in the catenary stage.

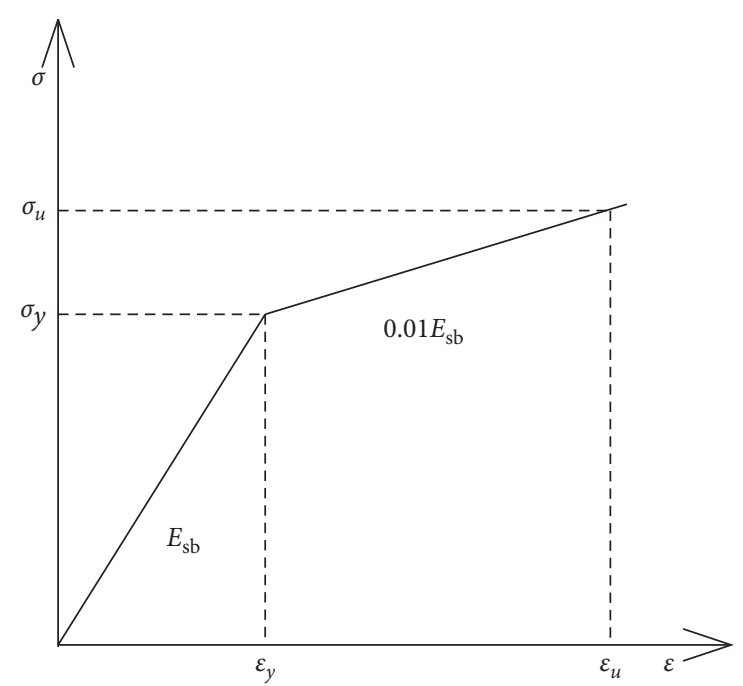

Figure 11: Stress-strain relationship in the catenary stage.

strengthening model considering the material strainstrengthening effect.

(3) The strain of the steel beam section, including the bending strain and the axial strain, conformed to the Euler-Bernoulli assumption, and its value increased to 0.02 , resulting in the structural damage.

The strain of the steel beam section at the start and end of this stage can be expressed as

$$
\varepsilon=\left\{\begin{array}{l}
\varepsilon_{N_{1}}=\varepsilon_{M_{u}} \\
\varepsilon_{N_{2}}=\varepsilon_{u}-\varepsilon_{M_{u}}
\end{array}\right.
$$

When strain reaches $\varepsilon_{N_{2}}$ from $\varepsilon_{N_{1}}$, strain energy per volume $(\kappa)$ can be calculated as

$$
\begin{aligned}
\kappa & =\int_{\varepsilon_{N_{1}}}^{\varepsilon_{N_{2}}} \sigma \mathrm{d} \varepsilon \\
& = \begin{cases}\int_{\varepsilon_{N_{1}}}^{\varepsilon_{y}} E_{\mathrm{sb}} \varepsilon \mathrm{d} \varepsilon+\int_{\varepsilon_{y}}^{\varepsilon_{N_{2}}} 0.01 E_{\mathrm{sb}} \varepsilon \mathrm{d} \varepsilon, & \varepsilon_{N_{1}}<\varepsilon_{y}, \\
\int_{\varepsilon_{N_{1}}}^{\varepsilon_{N_{2}}} 0.01 E_{\mathrm{sb}} \varepsilon \mathrm{d} \varepsilon, & \varepsilon_{N_{1}} \geq \varepsilon_{y} .\end{cases}
\end{aligned}
$$

Then, the structural deformation energy can be described as

$$
\begin{aligned}
U & =\iiint_{v} \kappa \mathrm{d} v=2 \int_{0}^{L / 2} \kappa A_{\mathrm{tc}} \mathrm{d} l \\
& =2 \begin{cases}U_{1}+U_{2}, & \varepsilon_{N_{1}}<\varepsilon_{y}, \\
U_{3}, & \varepsilon_{N_{1}}>\varepsilon_{y},\end{cases} \\
U_{1} & =\int_{0}^{L / 2} \int_{\varepsilon_{N_{1}}}^{\varepsilon_{y}} \frac{k_{t} L \varepsilon}{2} \mathrm{~d} \varepsilon \mathrm{d} l, \\
U_{2} & =\int_{0}^{L / 2} \int_{\varepsilon_{y}}^{\varepsilon_{N_{2}}} \frac{0.01 k_{t} L \varepsilon}{2} \mathrm{~d} \varepsilon \mathrm{d} l, \\
U_{3} & =\int_{0}^{L / 2} \int_{\varepsilon_{N_{1}}}^{\varepsilon_{N_{2}}} \frac{0.01 k_{t} L \varepsilon}{2} \mathrm{~d} \varepsilon \mathrm{d} l, \\
k_{t} & =\frac{4}{\left(H_{c}^{3} / 12\left(E_{\mathrm{sc}} I_{\mathrm{sc}}+0.6 E_{c} I_{\mathrm{cc}}\right)\right)+\left(L / E_{\mathrm{sb}} A_{\mathrm{sb}}\right)},
\end{aligned}
$$

where $k_{t}$ is the axial stiffness of the steel beam.

When the strain reached the ultimate strain, depending on the structural geometry coordination relationship, the vertical displacement of the failure point can be expressed as

$$
w=\sqrt{(1+\varepsilon)^{2}-1} \frac{L}{2} .
$$

The work done by external forces at this stage was

$$
\begin{aligned}
W & =\left(P-P_{C}\right)\left(w-w_{P_{C}}\right) \\
& =\left(P-P_{C}\right)\left[\sqrt{(1+\varepsilon)^{2}-1} \frac{L}{2}-w_{P_{C}}\right] .
\end{aligned}
$$

Thus, on the basis of the principle of energy balance, the force at this stage can be calculated as

$$
P=P_{C}+\frac{2}{\sqrt{(1+\varepsilon)^{2}-1}(L / 2)-w_{P_{C}}} \begin{cases}U_{1}+U_{2} & \varepsilon_{N_{1}}<\varepsilon_{y} \\ U_{3} & \varepsilon_{N_{1}} \geq \varepsilon_{y}\end{cases}
$$

\section{Discussion}

4.1. Comparisons between Experimental and Theoretical Results. Table 2 lists the theoretical and experimental values of the CFSTSBF specimen, and their resistance curves are shown in Figure 12. 
TABle 2: Comparisons between calculations and experimental results.

\begin{tabular}{lccccc}
\hline$P(\mathrm{kN})$ & \multicolumn{5}{c}{$w_{P}(\mathrm{~mm})$} \\
& 11 & 73 & 123 & 190 & 330 \\
\hline Experiment & 108.53 & 179.85 & 195.88 & 201.18 & 137.13 \\
Calculation & 99.26 & 140.59 & 145.29 & 198.83 & 216.62 \\
Deviation (\%) & 9.33 & 27.93 & 34.82 & 1.18 & -36.7 \\
\hline
\end{tabular}

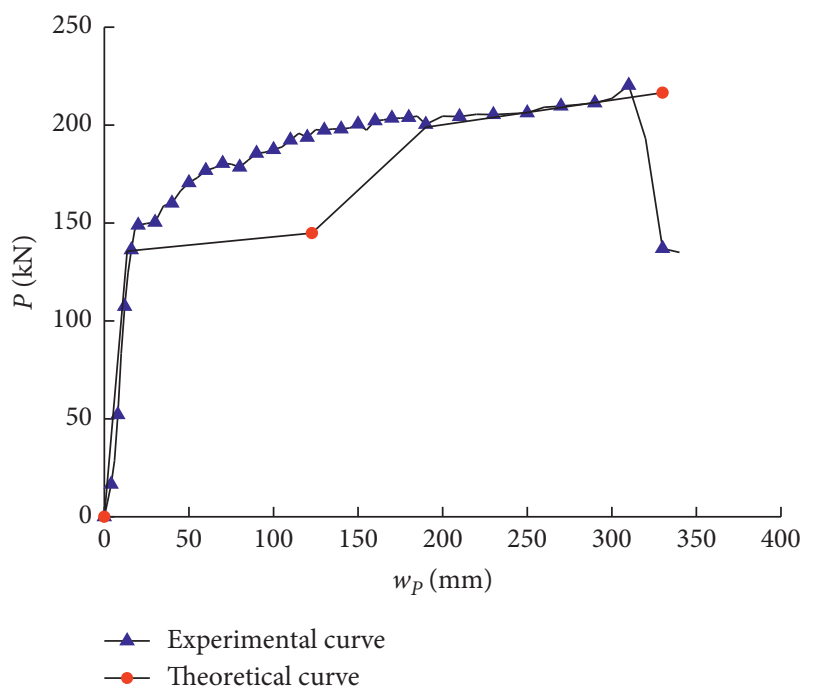

FIgURE 12: Resistance curves of the CFSTSBF specimen.

In the elastoplastic stage, the experimental value of initial rotational stiffness of the specimen, taking the secant stiffness at the initial yield point, was $8728.39 \mathrm{~N} / \mathrm{mm}$, while the theoretical value was $9340.69 \mathrm{~N} / \mathrm{mm}$, and the deviation between them was as few as $7.02 \%$. Thus, the elastoplastic model in this stage could better simulate the real response of the structure under the collapse condition case.

In the plastic stage, the deviation between the theoretical and experimental values started to expand (the latter was higher than the former).

In the transient stage, when the displacement was $123 \mathrm{~mm}$, the deviation reached a maximum of $34.82 \%$, and it then shrank gradually.

In the catenary stage, the theoretical values matched well with the test results, and when the vertical displacement reached $310 \mathrm{~mm}$, the test values began to decrease, whereas the theoretical value continued to increase. The main reason for this phenomenon was that firstly, the extensions of the plasticity status and the crack in the steel beam section were a slow process for the test duration, but their developments incurred the structural resistance to reduce; moreover, adopting the strain criterion as its failure criterion, the theoretical model would not fail until the strain reached its ultimate strain, which caused the resistance to increase.

As discussed previously, the analysis models simulated the whole collapse process of the specimen, and the calculations of the elastoplastic and catenary models could be well matched with the experimental results, indicating the

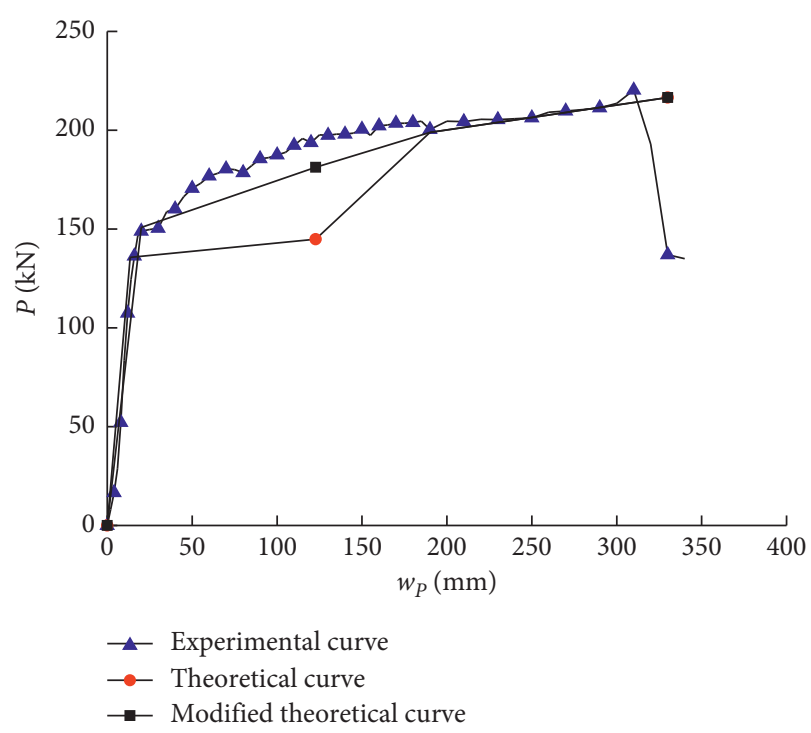

FIgURE 13: Resistance curves of the CFSTSBF specimen.

two analysis models could better reflect the structural real response in the corresponding stage.

4.2. Deviations Analysis and Theoretical Formula Modification. As can be seen in Table 1 and Figure 12, the major deviation between calculations and experimental results occurred in plastic and transient stages for the following reasons: the steel material constitutive relation of theoretical models adopted the ideal elastoplastic model taking no account of the strain-strengthening effect, and the plastic model omitted the contribution of axial force. Evidence from the test revealed the plastic strain of the steel beam was small and its section had not completely yielded yet at the end of the plastic stage. Thus, the theoretical analysis model in the plastic stage should incorporate the contribution of axial force.

Owing to that bending moment and axial force varied with the process of collapse and the steel beam section had not completely yielded, the relationship between the ultimate bending moment $\left(M_{u}\right)$ and the ultimate axial force $\left(N_{u}\right)$ of the steel beam section could not be determined in the plastic stage. As a consequence, it was impossible to develop the plastic model incorporating axial force and bending moment. Using the concept of approximation in the numerical analysis method, and assuming the theoretical model in the plastic stage meeting the basic assumptions mentioned above and the section deformation satisfying the deformation coordination condition, the present research deduced the structural resistance, and the detailed derivation process is as follows:

(1) Using the plastic stage resistance-deformation calculation formulae (equations (9) (19)), the structural resistance $P_{0}$ and the displacement $w_{0}$ of the failure point were obtained.

(2) Under the deformation coordination condition, the axial strain of the steel beam was derived at the moment of the displacement of the failure point $w$. 
(3) By substituting $P_{0}$ and $w$ into equation (38), the structural resistance $P_{1}$ was obtained:

$$
P_{1}=P_{0}+\mu E A \frac{\sqrt{\left[(L / 2)^{2}+w_{0}^{2}\right]^{2}}}{L / 2} .
$$

(4) The structural resistances $P_{0}$ and $P_{1}$ were compared. If their deviation met the practical accuracy requirement, the calculation process terminated; but if not, the responding displacement $w_{1}$ was calculated by substituting $P_{1}$ into equations (14) (19), and the above steps were repeated until the accuracy satisfied the requirement. The formula for calculating resistance could be expressed as

$$
P_{n}=P_{n-1}+\mu E A \frac{\sqrt{\left[(L / 2)^{2}+w_{n-1}^{2}\right]^{2}}}{L / 2} .
$$

The modified load-displacement curve of the CFSTSBF specimen is shown in Figure 13. The maximum deviation of the resistance of the structure after one approximation modification was reduced to $7.33 \%$ from $34.82 \%$, which basically met the practical accuracy requirements.

\section{Conclusions}

The present paper conducted the theoretical and experimental investigations on the progressive collapse resistance of the CFSTSBF specimen, based on the energy principlederived resistance-deformation functions, and drew the main conclusions as follows:

(1) The theoretical models, comprising 4 staged models, could better simulate the whole process of structural collapse, and each model represented the corresponding collapse stage of the CFSTSBF specimen. Validating against the test results, the resistancedeformation functions obtained from the theoretical models were good at reflecting the development trend of collapse, but weak at calculating accuracy. And the functions modified with the approximation method had high precision and well matched with the test results.

(2) When calculating the equivalent stiffness of steel beams, the restraining effect of concrete-filled square steel tubular columns and the influence of the plastic development of steel beam sections on the bending stiffness of steel beams should be taken into account.

(3) The strain criterion used in the theoretical analysis better simulated the failure characteristics of structures and components under collapse conditions and could be used as a criterion for the progressive collapse of steel beam frames.

\section{Notations}

\author{
$f_{y}: \quad$ Yield strength \\ $f_{y}$ : $\quad$ Ultimate tensile strength
}

$h$ : Sectional height of the steel beam

$b$ : $\quad$ Flange width of the steel beam

$t_{w}$ : Web thickness of the steel beam

$t_{w}$ : $\quad$ Flange thickness of the steel beam

$a$ : Sectional dimension of the steel tube

$t_{c}$ : Thickness of the steel tubular wall

$\mu_{\mathrm{EP}}$ : Flexural stiffness reduction factor in the elastoplastic stage

$\mu_{P}: \quad$ Flexural stiffness reduction factor in the plastic stage

$U: \quad$ Deformation energy

$V$ : $\quad$ Potential energy

$\Pi$ : $\quad$ Total potential energy

$E_{\mathrm{sb}}$ : Elastic modulus of the steel beam

$I_{\mathrm{sb}}$ : Sectional moment of inertia of the steel beam

$A_{\mathrm{sb}}$ : Sectional area

L: $\quad$ Beam span

$I_{c}$ : Column sectional moment of inertia

$H_{c}$ : Column height

$E_{\mathrm{sc}}: \quad$ Elastic modulus of the steel tube

$E_{c}$ : $\quad$ Elastic modulus of steel-concrete

$I_{\mathrm{sc}}$ : Sectional moment of inertia of the steel tube

$I_{\mathrm{cc}}$ : Sectional moment of inertia of concrete

$k_{E}$ : $\quad$ Equivalent bending stiffness of steel beams

$k_{t}$ : Axial stiffness of the steel beam

$M_{y}$ : Yield bending moment of the steel beam

$M_{u}$ : $\quad$ Ultimate bending moment of the steel beam

$\triangle P: \quad$ Vertical load increment applied on column $\mathrm{B}$

$\Delta P_{B}: \quad$ Vertical load increment in the plastic stage

$\Delta P_{C}:$ Vertical load increment in the transient stage

$w$ : Vertical displacement of the failure point

$\Delta w_{P_{B}}$ : Vertical displacement increment of the failure point in the plastic stage

$\Delta w_{P_{C}}$ : Vertical displacement increment of the failure point in the transient stage.

\section{Data Availability}

The data used to support the findings of this study are included within the article.

\section{Conflicts of Interest}

The authors declare that they have no conflicts of interest.

\section{Acknowledgments}

The support of the National Natural Science Foundation of China (no. 51178259) and Key R\&D Project of Shandong Province (no. 2018GSF120016) is gratefully acknowledged. This work was also supported by the Opening Foundation of Shandong Key Laboratory of Civil Engineering Disaster Prevention and Mitigation (no. CDPM2019KF06) and Weifang University Doctoral Research Initiation Fund (no. 2019BS17).

\section{References}

[1] B. R. Ellingwood and D. O. Dusenberry, "Building design for abnormal loads and progressive collapse," Computer-Aided 
Civil and Infrastructure Engineering, vol. 20, no. 3, pp. 194205, 2005.

[2] ASCE/SEI 7-10, Minimum Design Loads for Buildings and Other Structures [S], American Society of Civil Engineering, Reston, VA, USA, 2006.

[3] B. R. Ellingwood, "Mitigating risk form abnormal loads and progressive collapse," Journal of Performance of Constructed Facilities, vol. 20, no. 3, pp. 315-323, 2006.

[4] Z. P. Bažant and M. Verdure, "Mechanics of progressive collapse: learning from world trade center and building demolitions," Journal of Engineering Mechanics, vol. 133, no. 3, pp. 308-319, 2007.

[5] GSA2013, Alternate Path Analysis and Design Guidelines for Progressive Collapse Resistance, American General Services Administration, Washington, DC, USA, 2013.

[6] DOD2013, Design of Buildings to Resist Progressive Collapse, Department of Defense, Washington, DC, USA, 2013.

[7] Y. Q. Guo and J. Yu, "Dynamic structural response of progressive collapse under a single-column-removal scenario," Engineering Mechanics, vol. 34, no. 4, pp. 72-77, 2017, in Chinese.

[8] M. Ferraioli, "A modal pushdown procedure for progressive collapse analysis of steel frame structures," Journal of Constructional Steel Research, vol. 156, pp. 227-241, 2019.

[9] O. A. Harry and Y. Lu, "Simplified theoretical model for prediction of catenary action incorporating strength degradation in axially restrained beams," Engineering Structures, vol. 191, pp. 219-228, 2019.

[10] J.-Z. Zhang, G.-Q. Li, Y.-B. Wang, and J. Jiang, "Theoretical investigations on load-bearing capacity of RC flat-plate framed structures subject to middle column loss," The Structural Design of Tall and Special Buildings, vol. 27, no. 6, p. e1458, 2018.

[11] A. T. Pham and K. H. Tan, "Analytical model for tensile membrane action in RC beam-slab structures under internal column removal," Journal of Structural Engineering, vol. 145, no. 6, Article ID 04019040, 2019.

[12] X. Lu, K. Lin, C. Li, and Y. Li, "New analytical calculation models for compressive arch action in reinforced concrete structures," Engineering Structures, vol. 168, pp. 721-735, 2018.

[13] H. Xiao and B. H. Flexural, "Compressive arch, and catenary mechanisms in pseudostatic progressive collapse analysis," Journal of Performance of Constructed Facilities, vol. 32, no. 1, Article ID 04017115, 2018.

[14] B. A. Izzuddin, A. G. Vlassis, A. Y. Elghazouli, and D. A. Nethercot, "Progressive collapse of multi-storey buildings due to sudden column loss-part I: simplified assessment framework," Engineering Structures, vol. 30, no. 5, pp. 1308-1318, 2008.

[15] H. Choi and J. Kim, "Progressive collapse-resisting capacity of RC beam-column sub-assemblage," Magazine of Concrete Research, vol. 63, no. 4, pp. 297-310, 2011.

[16] B. L. Zhu, Structure Seismic Test, Seismological Press, Beijing, China, 1989, in Chinese.

[17] GJ101-96, Specificating of Testing Methods for Earthquake Resistant Building, China Architecture \& Building Press, Beijing, China, 1997, in Chinese.

[18] Y. Zhou, T. P. Chen, X. Hu, and W. J. Yi, "Progressive collapse resistance of RC frame structures considering surrounding structural constraints," Engineering Mechanics, vol. 36, no. 1, pp. 216-226, 2019, in Chinese.

[19] D. O. Dusenberry and R. O. Hamburger, "Practical means for energy-based analyses of disproportionate collapse potential,"
Journal of Performance of Constructed Facilities, vol. 20, no. 4, pp. 336-348, 2006.

[20] K. Q. Wang, G. Q. Li, and T. C. Yang, "A study of resitrained steel beams with catenary action under distributed load-part 1: theoretical model," Civil Engineering Journal, vol. 43, no. 1, pp. 1-7, 2010, in Chinese. 


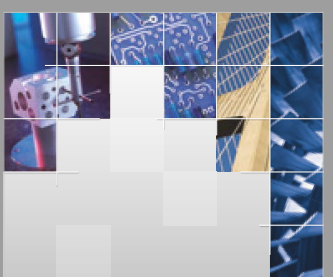

\section{Enfincering}
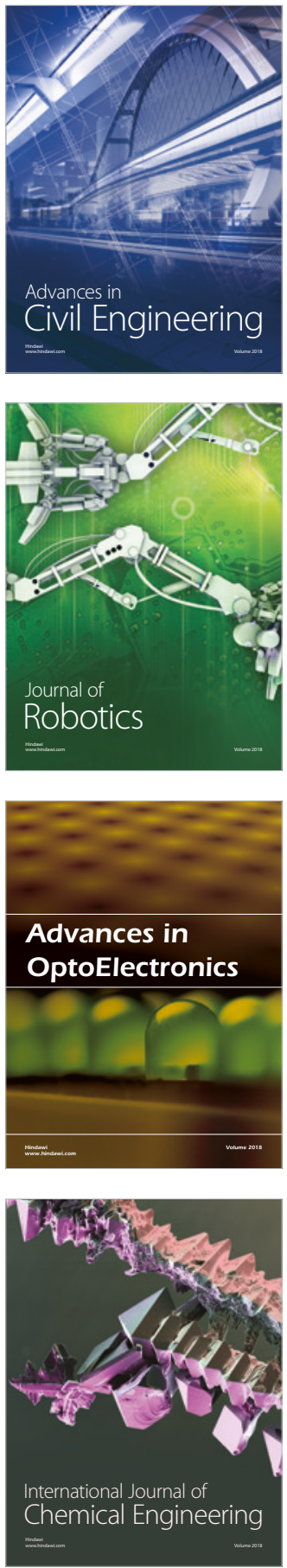

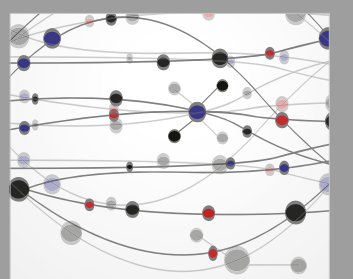

\section{Rotating \\ Machinery}

The Scientific World Journal

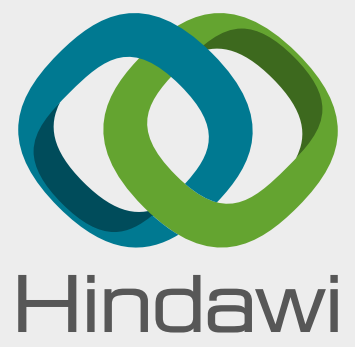

Submit your manuscripts at

www.hindawi.com
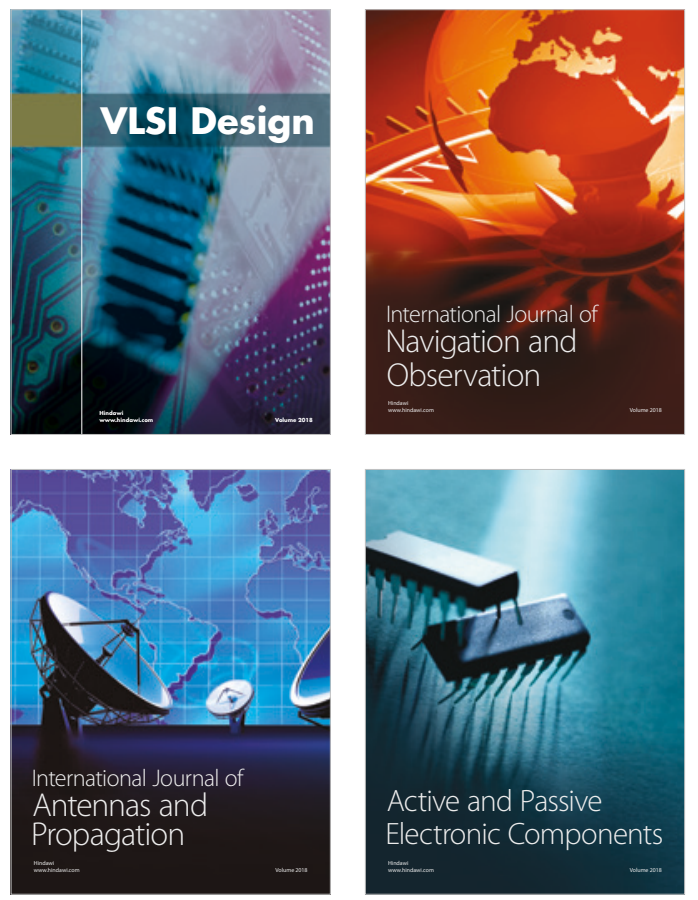
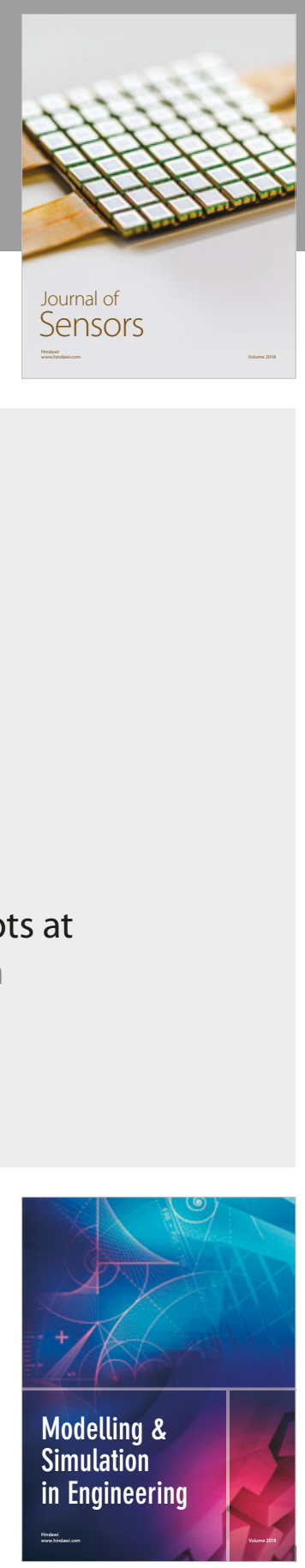

\section{Advances \\ Multimedia}
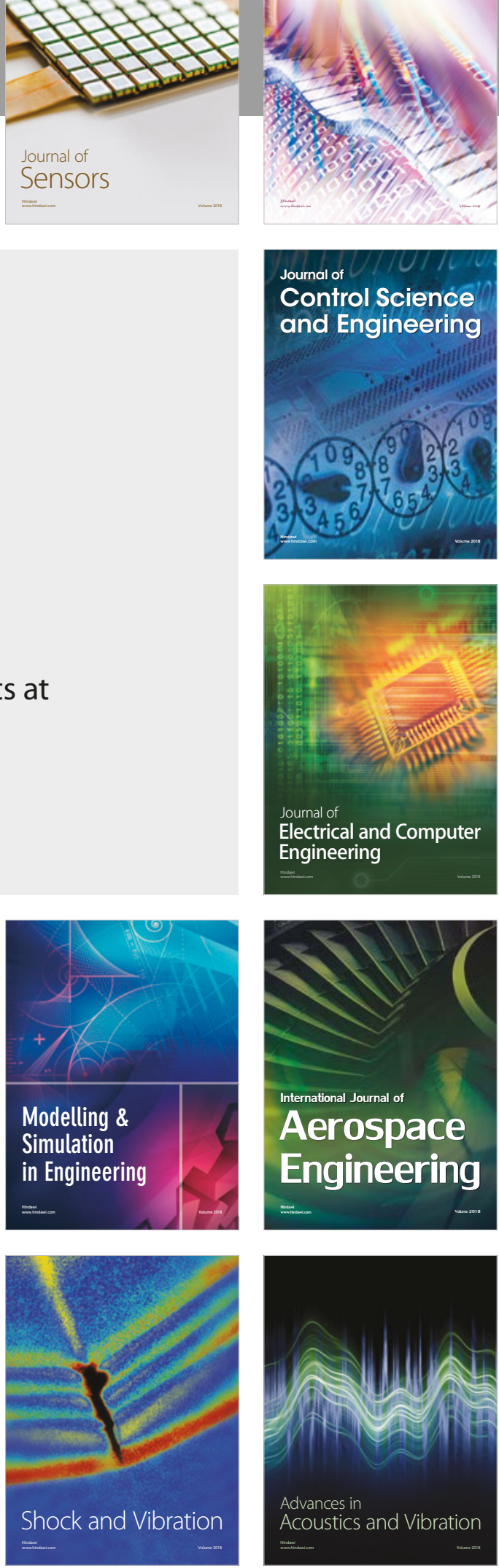